\title{
The Effects of Moral Judgment and Moral Identity on Moral Behavior: An Empirical Examination of the Moral Individual
}

\author{
Scott J. Reynolds and Tara L. Ceranic \\ University of Washington Business School
}

\begin{abstract}
Recognizing limitations in classic cognitive moral development theory, several scholars have drawn from theories of identity to suggest that moral behavior results from both moral judgments and moral identity. The authors conducted 2 survey-based studies with more than 500 students and managers to test this argument. Results demonstrated that moral identity and moral judgments both independently influenced moral behavior. In addition, in situations in which social consensus regarding the moral behavior was not high, moral judgments and moral identity interacted to shape moral behavior. This interaction effect indicated that those who viewed themselves as moral individuals pursued the most extreme alternatives (e.g., never cheating, regularly cheating) — a finding that affirms the motivational power of a moral identity. The authors conclude by considering the implications of this research for both theory and practice.
\end{abstract}

Keywords: moral judgment, ethical predispositions, moral identity, social consensus, moral behavior

Recent ethical scandals, such as those associated with Enron and stock options backdating, have reconfirmed the value and importance of understanding moral behavior and increased the attention paid to moral decision making and moral behavior research (see Treviño, Weaver, \& Reynolds, 2006, for a full review). Although the field of business ethics has long been grounded in a cognitive approach (e.g., Kohlberg, 1981; Rest, 1986), several scholars have cited limitations of classic cognitive developmental theory and called for alternative approaches (e.g., Haidt, 2001; Reynolds, 2006b). For example, some have referred to identity theories (Blasi, 1984; Aquino \& Reed, 2002), social identity theory in particular (Tajfel, 1959, 1974; Tajfel \& Turner, 1979; Turner \& Oakes, 1986), to suggest that the cognitive developmental approach fails to account for the individual's perception of the moral self and the constraints that an individual's self-conception has on his or her ability to see a moral judgment through to moral behavior. In short, these approaches argue that moral behavior is the result of both moral judgment and an individual's moral identity.

Though a great deal of research has explored the effects of moral judgment and moral identity on moral behavior separately, we sought to test the effects of both factors on moral behavior to determine whether such an integrated approach is empirically justified and, if so, how moral judgment and moral identity act independently and with each other to shape moral behavior. In this research, we used two different samples to explore the possibility that moral judgment and moral identity both influence moral

Scott J. Reynolds and Tara L. Ceranic, Department of Management and Organization, University of Washington Business School.

Special thanks go to Karl Aquino, Katherine DeCelles, Tom Lee, David Wasieleski, and Jim Weber for their help in developing this article.

Correspondence concerning this article should be addressed to Scott J. Reynolds, University of Washington Business School, Box 353200, Seattle, WA 98028. E-mail: heyscott@u.washington.edu behavior but that the influence and interaction of the two depend on the level of social consensus surrounding the moral issue in question. We sought to demonstrate that individuals do, indeed, rely on both moral judgments ("What is right and wrong?") and perceptions of themselves ("Who am I?") to act morally but that this relationship is more complicated than previously thought. Ultimately, this research provides evidence that an integrated approach to the study of moral behavior is not only justified but also informative.

\section{Moral Behavior and Its Antecedents}

The term moral or ethical behavior can refer to a wide range of behaviors. Following Treviño et al. (2006), we define moral and ethical behavior as behavior that is subject to (or judged according to) generally accepted moral norms of behavior. Thus, moral behaviors occur within the context of larger social prescriptions. This broad definition accounts for behaviors that are contrary to moral norms and are typically deemed immoral, such as lying, cheating, and stealing, as well as behaviors that reach or exceed some minimal moral standard and are normally considered to be ethical (or not unethical), such as being honest, obeying the law, and whistle-blowing. This definition captures both lay expectations of what moral behavior entails and social scientific precedents (e.g., Jones, 1991) found in the literature.

\section{Moral Judgments-Consequentialism and Formalism}

To date, the most common framework used to explore moral behavior has been a cognitive approach (e.g., Kohlberg, 1984). The cognitive approach is most aptly characterized by Rest's (1986) four-stage model of the moral decision-making process. According to Rest, moral decision making begins with an awareness of the moral issue. The individual then makes a moral judgment, establishes an intention to act morally, and, finally, engages in moral behavior. Kohlberg (1981) argued that though 
there are many elements that contribute to moral behavior, the most critical element is moral judgment, or determining what is right and wrong. Much of the research on this topic has measured moral judgment as stages of moral development (e.g., Abdolmohammadi \& Sultan, 2002; Bernardi et al., 2004; Goolsby \& Hunt, 1992; Green \& Weber, 1997; Greenberg, 2002; Kohlberg, 1984), but other alternatives have also been utilized (e.g., Forsyth, 1985; Fraedrich, 1993; Henle, Giacalone, \& Jurkiewicz, 2005; Hunt \& Vasquez-Parraga, 1993). Perhaps the most fundamental alternative for conceptualizing and measuring moral judgments is ethical predisposition.

Ethical predisposition refers to the cognitive frameworks individuals rely on when facing moral decisions (Brady \& Wheeler, 1996). Research in this area has focused on two of the most foundational moral frameworks: consequentialism and formalism. Consequentialism ${ }^{1}$ represents teleological or ends-based decision making. It focuses attention on the ends of an act and contends that the moral act is that which optimizes or creates the greatest good or benefit (Brady, 1985). In contrast, formalism represents deontological or obligation-based approaches to morality (Kant, 1785/ 1994). This framework emphasizes the importance of patterns, rules of behavior, and other formal standards to determine moral behavior (Brady \& Wheeler, 1996; Honderich, 1995). Research has demonstrated that preferences for consequentialism and formalism can influence moral awareness (Reynolds, 2006a), moral decisions (Brady \& Wheeler, 1996), and perceptions of justice (Schminke, Ambrose, \& Noel, 1997). Although research has firmly established that moral judgment (e.g., consequentialism, formalism) shapes moral behavior (Treviño et al., 2006), this work has also demonstrated that moral judgment does not explain all of the variance in moral behavior, as Kohlberg $(1981,1984)$ and others theorized (see Blasi, 1980; Haidt, 2001). Therefore, we draw from existing theory and research to suggest that moral identity is also a critical determinant of moral behavior.

\section{Moral Identity}

An identity is a self-conception or a self-definition (Erikson, 1964). A moral identity is a specific kind of identity that revolves around the moral aspects of one's self (Bergman, 2002). A moral identity acts as a self-regulatory mechanism that sets parameters for individual behavior and motivates specific action that is moral (e.g., Blasi, 1984; Damon \& Hart, 1992; Erikson, 1964). The motivating force of a moral identity is explained by the consistency principle, which states that an identity creates a need for the individual to be true to himself or herself and, therefore, the need to act consistently with his or her identity (Erikson, 1964). A strong moral identity thus compels the individual to act in a moral manner (Colby \& Damon, 1992; Oliner \& Oliner, 1988).

Aquino and Reed (2002) drew from social identity theory (Tajfel, 1959, 1974; Tajfel \& Turner, 1979; Turner \& Oakes, 1986) to argue that a moral identity can be organized around traits associated with moral behavior. They referenced the consistency principle and suggested that, to the extent an individual adopts and/or aspires to moral traits, that individual is driven to act in a way that is consistent with these traits. Aquino and Reed empirically identified two dimensions of moral identity: internalization and symbolization. Internalization reflects the degree to which a set of moral traits is central to the self-concept, whereas symbolization reflects the degree to which these traits are expressed publicly through a person's actions in the world. Aquino and Reed demonstrated that these dimensions effectively predict several moral behaviors, including self-reported volunteering and the willingness to minimize harm (Aquino \& Reed, 2002; Reed \& Aquino, 2003). Nevertheless, Aquino and Reed (2002) clearly stated that "moral identity does not supplant the cognitive-developmental model or the idea of moral reasoning as a predictor of moral action. Rather it complements this approach" (p. 1425).

Given the large body of empirical evidence on these topics, we propose that moral judgment (consequentialism and formalism) and moral identity (internalization and symbolization) each shape moral behavior. We further suggest that moral behavior can be influenced by an interaction of moral judgment and moral identity but that these relationships depend on the level of social consensus associated with the specific moral issue involved. In the following section, we discuss social consensus in greater detail and clarify its role in shaping moral behavior. Then, on the basis of a distinction between issues that are high and not high in social consensus, we specify models that detail the relationships of moral judgment (consequentialism and formalism), moral identity (internalization and symbolization), and moral behavior.

\section{Social Consensus}

Social consensus refers to the degree of social agreement regarding whether a proposed act is good or evil (Jones, 1991) or right or wrong. It is one of six defined characteristics that specify the moral intensity of an issue, the extent to which the issue is subject to moral consideration, moral judgment, and moral action (Jones, 1991). Whereas the other five characteristics of moral intensity (magnitude of consequences, concentration of effects, probability of effect, temporal immediacy, and proximity) are strictly descriptive in nature, social consensus contains a strong normative element (Weaver \& Treviño, 1994). Social consensus indicates the extent to which there is a general concurrence within society about the moral status of the issue. Although no specific referent is stipulated, social consensus communicates a general normative conclusion, a broad social judgment about that issue. In situations of high social consensus, there is widespread agreement on the moral status of the issue (e.g., incest). In situations in which social consensus is not high, however, there is more disagreement about what constitutes a moral act in that situation (e.g., jaywalking).

Given this unique normative aspect, we believe that social consensus can decrease the need for individual moral judgment. As Jones (1991) argued, "it is difficult to act ethically if a person does not know what good ethics prescribes in a situation; a high degree of social consensus reduces the likelihood that ambiguity will exist" (p. 375). By reducing ambiguity about what is right and wrong, social consensus can minimize the need for individual moral judgment. Thus, we suggest that the influence of consequen-

\footnotetext{
${ }^{1}$ In the past, researchers have referred to this framework as utilitarianism, after the most well-known teleological theory (Mill, 1863/1987). The framework, however, represents more than just utilitarian ideals - it also accounts for egoistic ends-based decisions. Therefore, we refer to it here by the more general term of consequentialism.
} 
tialism and formalism on moral behavior varies according to the level of social consensus associated with the specific moral issue.

In situations of high social consensus (see Figure 1), there is a great deal of social agreement as to what is right and what is wrong. Given a high level of social agreement, the individual can subjugate his or her own moral judgment and rely on the normative assertions of society to determine right and wrong. Subsequently, the only meaningful question for the individual to answer is one of motivation-to what extent does he or she want to commit the moral act? In other words, the individual only need determine to what extent he or she will act according to that social consensus (e.g., wholeheartedly, halfheartedly, not at all). Thus, we theorize that in situations of high social consensus, neither consequentialism nor formalism will have a significant effect on moral behavior, whereas internalization and symbolization will have positive direct effects on moral behavior.

We recognize that research has demonstrated a link between moral judgment and moral behavior, but we also note that no research has considered the possibility that social consensus can affect this relationship. Further, we note that empirical evidence supports our view. In the moral judgment literature, Laczniak and Inderrieden (1987) found that individuals were less likely to engage in strictly illegal behavior as opposed to unethical behaviors, a finding they attributed to a higher level of social agreement about the appropriateness of illegal behaviors. In the identity literature, Aquino and Reed (2002) examined several behaviors that, in retrospect, are generally recognized as having high social consensus: volunteering, donating food, and donating money. Their results demonstrated that moral identity positively influenced these moral behaviors (although the authors did not control for moral
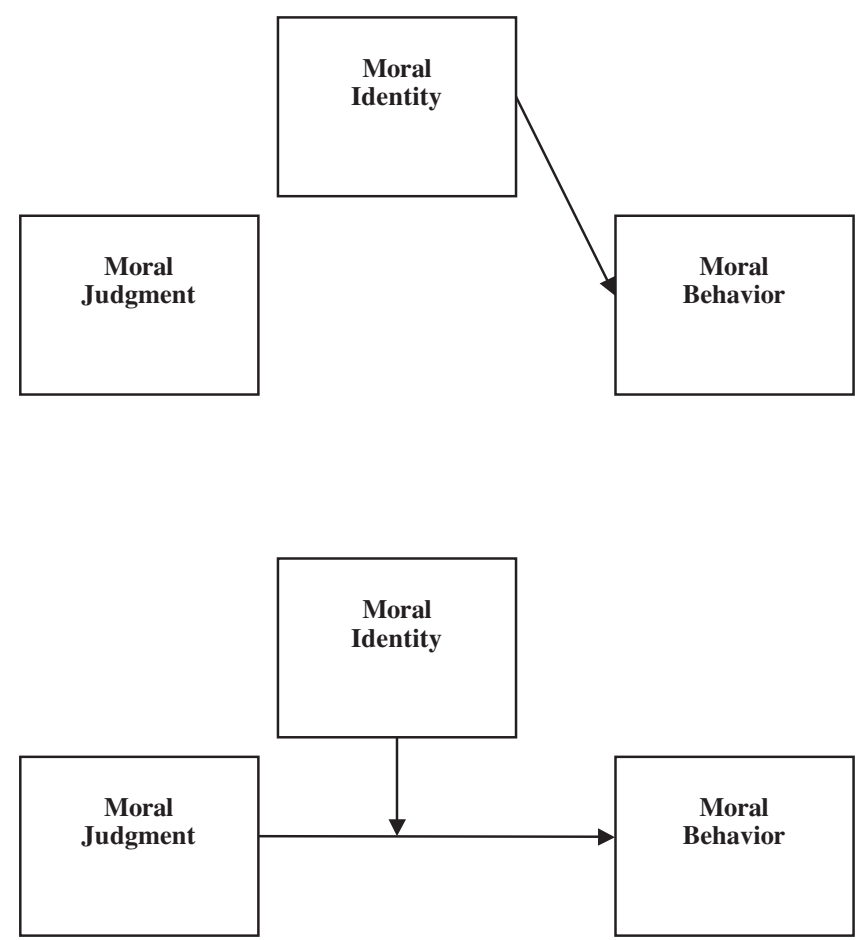

Figure 1. Proposed relationships when social consensus regarding the moral issue is high (top panel) and when it is not high (bottom panel). judgments). We suggest that in all of these situations, social consensus made the moral behavior apparent, and thus individual moral judgment was less necessary. In addition, as Aquino and Reed's research demonstrated, in such situations internalization and symbolization predicted moral behavior. Thus, we present Hypothesis 1:

Hypothesis 1: When social consensus regarding the moral issue is high, internalization and symbolization will positively influence moral behavior even after the effects of consequentialism and formalism are accounted for.

In situations in which social consensus is not high (Figure 1), the influence of moral judgment and moral identity on moral behavior is slightly more complicated. If social consensus is not high, the moral course of action is not obvious. Indeed, these kinds of situations are often referred to as moral dilemmas, precisely because several or all of the possible alternatives have a strong moral justification; thus, there is little consensus about what to do (Badaracco, 1997; Toffler, 1986). In such situations, the individual must first identify which course of action is the moral alternative (judgment) and then determine how fully to commit to that action (motivation).

We propose that in situations in which social consensus is not high, consequentialism and formalism exert direct main effects on moral behavior, thus dictating whether the individual will choose a more consequentialistic (valuing ends over means) or formalistic (valuing means over ends) alternative. In turn, internalization and symbolization as motivational forces moderate these relationships, determining the extent to which the individual will pursue or fulfill that alternative. Together, moral judgment and moral identity determine the direction and the motivation for the specific moral behavior.

Both theory and empirical evidence support this interaction argument. For example, Damon (1984) referenced his research with children and argued that during adolescence children experience an integration of "morality and the self" (p. 119) in which concerns about their personal identity are considered jointly with more objective concerns about what is morally right. Similarly, Blasi (1989) conducted studies with young children and noted differences between the moral narratives of young children and older children with developed identities, concluding that "what is needed is a certain kind of integration of moral understanding in one's personality" (p. 125). To this end, Bergman (2002) suggested that an integration of morality and identity is the height of moral maturity. Narvaez, Getz, Rest, and Thoma (1999) surveyed congregation members and found that opinions on public policy were shaped by moral judgments and political identity (and also religious fundamentalism), a variable the researchers treated as a "combined measure." In addition, Moreland and Leach (2001) surveyed 197 African Americans and found evidence to suggest that racial identity interacts with moral development to determine an individual's willingness to apply his or her most developed moral frameworks. Though neither of these last two studies focused on moral identities, we believe that a moral identity is likely more relevant to explaining moral behavior than is any other type of identity. Finally, we recognize that a host of research on expectancy theory and its variants (Fishbein \& Azjen, 1975; Vroom, 1964) has demonstrated that behavior is shaped by an 
interaction between expectations about which course of action is most likely to achieve an outcome and the expected value of that outcome (Mitchell \& Daniels, 2002). In the case of moral behavior, we suggest that outcomes are likely to be moral to the degree that they are judged to meet moral standards, and they are desirable to the extent that they satisfy the needs of the individual's identity. Thus, in situations in which the social consensus regarding the moral behavior is not high, moral behavior is the result of an interaction between expectations about what is moral (moral judgment) and identity-related expectations of the value of that behavior.

In short, we propose that when social consensus is not high, consequentialism and formalism exert direct effects on moral behavior, resulting in more consequentialistic or formalistic behaviors. In addition, the moral identity dimensions of internalization and symbolization each interact with consequentialism and formalism to affect moral behavior, such that the greater the moral identity dimension is, the more an individual's preference for consequentialism leads to consequentialistic outcomes, and the more an individual's preference for formalism leads to formalistic outcomes. Compared to symbolization, internalization is theoretically more consistent with the principle of moral motivation, reflected in discussions of such concepts as fortitude and moral courage (Cavanagh \& Moberg, 1999; Rest, 1986); therefore, we expect internalization to be a stronger predictor of moral behavior. Nevertheless, as scholars have yet to identify meaningful differences between the two dimensions, our hypotheses account for both dimensions. Our arguments are summarized below:

Hypothesis 2a: When social consensus regarding the moral issue is not high, consequentialism will be positively associated with more consequentialistic moral behavior even after the effects of internalization and symbolization are accounted for.

Hypothesis 2b: When social consensus regarding the moral issue is not high, formalism will be positively associated with more formalistic moral behavior even after the effects of internalization and symbolization are accounted for.

Hypothesis 3a: When social consensus regarding the moral issue is not high, internalization (and symbolization) will interact with consequentialism such that greater internalization (symbolization) and a greater preference for consequentialism will result in a more consequentialistic moral behavior.

Hypothesis 3b: When social consensus regarding the moral issue is not high, internalization (and symbolization) will interact with formalism such that greater internalization (symbolization) and a greater preference for formalism will result in a more formalistic moral behavior.

In the following sections, we report two studies that test these hypotheses. The first study involved a student sample. To explore the effects of moral judgments and moral identity on moral behavior, in Study 1 we focus on charitable giving as a moral behavior high in social consensus (Hypothesis 1) and cheating as a moral behavior not high in social consensus (Hypotheses 2-5). In
Study 2 we seek to extend the generalizability of the results from Study 1 (Hypotheses 2-5) by employing a managerial sample and two additional measures of moral behavior not high in social consensus: an ethical behavior scale and a vignette.

\section{Study 1: A Survey on Charitable Giving and Cheating}

\section{Method}

\section{Sample}

Participants in this study were 226 students who were enrolled in multiple sections of an upper level business school management course. The sample consisted of 119 men and 105 women (2 participants did not indicate their sex) who ranged in age from 18 to 44 years $(M=21.3, S D=2.98)$. Fifty-nine percent $(133)$ of the participants identified themselves as juniors, and most (94\%) were business majors. Forty-six percent were Caucasian, $43.8 \%$ were Asian, and $9.3 \%$ identified themselves as being in other ethnic categories.

\section{Procedure}

The instrument was a secure online survey that recorded anonymous responses. Students who were enrolled in the course (approximately 350 ) were informed of the survey via an e-mail from the course coordinator, an instructor of one of the course sections. The students were notified that completing the study satisfied a course research requirement, although other, comparable alternatives were also available. Participants completed the survey outside of their regular class time. After completing the survey, each participant printed a generic confirmation page to submit to his or her instructor for course credit. Recent research has demonstrated that Web-based methods of collecting data yield results comparable to those from more traditional (e.g., paper and pencil) formats (e.g., Krantz \& Dalal, 2000).

\section{Measures}

Dependent variable-charitable giving. Given Aquino and Reed's (2002) results in this area, we identified charitable giving as a moral behavior with potentially high social consensus (Ray, 1998). We measured charitable giving with three items. Participants responded on a 4 -point scale $(1=$ never, $4=$ many times $)$ to indicate how often during college they had volunteered for a good cause (homeless shelters, Sub for Santa, etc.), donated non-money items (clothes, food, etc.) to the needy, and donated to a charity. The reliability figure for the three items was .73.

Dependent variable-cheating. We identified cheating as a moral behavior relevant to this group and potentially not high in social consensus. Cheating behaviors are tactics used by students to achieve an unfair advantage over other students in a course. They include blatant attempts to raise tests scores, such as using crib notes and copying answers, and more subtle forms, such as falsifying a bibliography, receiving prohibited help on an assignment, or not informing an instructor of a mistake made in grading (McCabe \& Treviño, 1993). Traditionally, cheating has been viewed as a "right versus wrong" decision. From a formalistic perspective, cheating violates principles of honesty and fairness to others and is thus considered to be immoral. Changing environ- 
mental and cultural conditions in recent years, however, have made the consequentialistic perspective regarding cheating behaviors much less clear (Callahan, 2004). The popularity of graduate schools has fueled perceptions of undergraduate education as a stepping stone. Moreover, cheating is seen as having no immediate harmful effects, and any long-term effects are greatly dispersed (across the class or across the university; Jones, 1991). In addition, students' own observations of widespread cheating and few, if any, negative ramifications suggest that the risks of getting caught and being severely punished are extremely low. As a result, some students view cheating as a low-risk and harmless activity with potentially huge benefits, both for the individual and for those whom the individual can later benefit with his or her degree (e.g., family members, society). Given this kind of a cost-benefit analysis, cheating seems to be a morally valid course of action. While a more objective observer might argue that this particular consequentialistic argument is deeply flawed, empirical evidence suggests that many students believe the argument to be true. Students regularly identify themselves as moral individuals (Ford \& Richardson, 1994), yet cheating is at near-rampant levels (McCabe \& Treviño, 1993, 1996). Recognizing these circumstances, we theorized that social consensus regarding cheating would not be high, and, thus, cheating could serve as a basis for investigating the role of moral judgment and moral identity on moral behavior.

Cheating behavior was measured with items developed by McCabe and colleagues (e.g., McCabe \& Treviño, 1993; McCabe, Treviño, \& Butterfield, 1996). Participants indicated to what extent $(1=$ never, $4=$ many times $)$ they had engaged in each of 13 cheating behaviors (e.g., using crib notes, turning in work done by someone else) while in college. The reliability coefficient for this scale was .75. Per Brady and Wheeler's (1996) distinctions, higher incidences of cheating constituted a more consequentialistic solution (benefits outweigh costs), and lower incidences of cheating represented a more formalistic solution (cheating violates rules).

Evidence regarding the validity of the two dependent variables was gathered from a second sample of students. A comparable sample of 45 undergraduate students in a management course at an East Coast university (age: $M=21.1, S D=1.05 ; 60 \%$ male; $56.8 \%$ seniors) was presented with the three charitable giving behaviors described previously and asked, "In your opinion, to what extent do college students agree that the following behaviors are morally good things to do?" Social consensus was measured with one item on a 5-point Likert-type scale with scores ranging from 1 (there is a great deal of disagreement) to 5 (there is a great deal of agreement). The students were also presented with the 13 cheating behaviors discussed above and asked, "In your opinion, to what extent do college students agree that the following behaviors are morally wrong?" An identical 5-point scale was used.

The results indicated that the students believed that charitable giving behaviors involve a high degree of social consensus $(M=$ $4.79, S D=0.41)$, whereas cheating behaviors do not $(M=3.82$, $S D=0.81$ ). Paired sample $t$ tests indicated a significant difference between the two responses, $t(44)=7.96, p<.01$, and the effect size $(d=1.51)$ indicated a large effect. Though we would not characterize social consensus regarding cheating behaviors as low, both the means and the test confirming their statistical differences provided evidence that charitable giving was an issue high in social consensus and cheating was an issue not high in social consensus.
Independent variables. Moral identity was measured with Aquino and Reed's (2002) internalization and symbolization scales. A programming error inadvertently resulted in the deletion of one of the internalization items ("Having these characteristics is not really important to me"), so participants received only 9 of the original 10 items. Despite the loss of the 1 item, principalcomponents analysis with varimax rotation revealed two distinct factors (Symbolization: eigenvalue $=3.77,41.9 \%$ of variance; Internalization: eigenvalue $=2.19,24.4 \%$ of variance) that each demonstrated acceptable reliability (Symbolization, $\alpha=.85$; Internalization, $\alpha=.83$ ), just as Aquino and Reed (2002; Reed \& Aquino, 2003) had previously demonstrated. In addition, the scales correlated, as expected, with two constructs Aquino and Reed (2002) argued should associate (negatively or positively) with a moral identity: normlessness and altruism. Normlessness is one's propensity to approve of situations in which there is a high expectancy that socially unapproved behaviors are required to achieve given goals, and altruism is one's acceptance of generalized responsibility to help, to share, and to be generous toward others. We measured normlessness with Kohn and Schooler's (1983) four-item scale and altruism with Ahmed and Jackson's (1979) eight-item scale. Internalization was significantly correlated with each $(r=-.33, p=.00 ; r=.32, p=.00$, respectively), and symbolization was significantly correlated with altruism $(r=$ $.04, p=.61 ; r=.13, p=.05$, respectively).

Consequentialism and formalism were measured with the Character Traits section of the Measure of Ethical Viewpoints (Brady \& Wheeler, 1996). The instrument lists character traits that respondents rate on a 7 -point scale $(1=$ not important to me, $7=$ very important to me). Consequentialism was measured with seven items ("innovative," "resourceful," "effective," "influential," "results-oriented," "productive," and "a winner"), and formalism was measured with six ("principled," "dependable," "trustworthy," "honest," "noted for integrity," and "law abiding"). The construct reliability measures were .75 for consequentialism and .79 for formalism. These findings are consistent with previous findings (Brady \& Wheeler, 1996; Reynolds, 2006a; Schminke et al., 1997).

To test the validity of the consequentialism and formalism measures, we conducted confirmatory factor analyses. We first compared a one-factor model to the theorized two-factor model. For the two models, $\Delta \chi^{2}(1, N=226)=308.82, p<.01$ (Anderson \& Gerbing, 1988). Further, the standardized fit statistics were all much greater for the two-factor solution than for the one-factor solution (change in comparative fit index $[\mathrm{CFI}]=.11$; change in normed fit index $[\mathrm{NFI}]=.11$, change in relative fit index $[\mathrm{RFI}]=$ .13; Widaman, 1985). These figures indicated that the two-factor solution fit significantly better than did the one-factor solution. In the two-factor solution, $\chi^{2}(64, N=226)=185.49$ (root-meansquare error of approximation [RMSEA] $=.09)$, and the standardized loadings of all of the items were significant $(p<.05)$. The comparative fit, incremental fit, and goodness-of-fit indexes (.94, .94 , and .89 , respectively) all exceeded Bentler and Bonett's (1980) recommended figures $(.92, .92$, and .86, respectively) and approached Hu and Bentler's (1999) more stringent standards (.95, .95 , and .90 , respectively). These results indicated an acceptable overall fit.

As the four independent variables represented very similar domains, we conducted a confirmatory factor analysis to examine the 
discriminant validity of the four measures. The $\Delta \chi^{2}$ between a one-factor model and a four-factor model was 1,418.81, which was significant at $p<.01(d f=3)$, (Anderson \& Gerbing, 1988). The standardized fit statistics were all much greater for the four-factor solution than for the one-factor solution $(\Delta \mathrm{CFI}=.23 ; \Delta \mathrm{NFI}=.22$; $\Delta \mathrm{RFI}=.24$; Widaman, 1985). In the four-factor solution, the standardized loadings of all of the items (see Table 1) were significant $(p<.05)$, and the chi-square, $\chi^{2}(203, N=226)=$ 486.13 , and RMSEA (RMSEA $=.08$ ) figures indicated an acceptable fit (Browne \& Cudeck, 1992). One of the items, "lawabiding," did not load strongly onto its latent construct, formalism. None of the subsequent analyses, however, were impacted by the inclusion or exclusion of this item, so we retained the item. The comparative fit, incremental fit, and goodness-of-fit indexes (.93, .93 , and .84 , respectively) approached the most stringent standards of acceptability (Hu \& Bentler, 1999). These results provide evidence of the convergent and discriminant validity of these four constructs.

Control. Although the survey was anonymous, we recognized that social desirability bias could strongly influence the responses of the participants. Therefore, we measured social desirability bias with 37 items from Paulhus's (1984) Balanced Inventory of De-

Table 1

Study 1: Results of Confirmatory Factor Analysis

\begin{tabular}{|c|c|}
\hline Item & Loading \\
\hline \multicolumn{2}{|l|}{ Consequentialism $^{\mathrm{a}}$} \\
\hline Innovative & .59 \\
\hline Resourceful & .63 \\
\hline Effective & .74 \\
\hline Influential & .69 \\
\hline Results-oriented & .57 \\
\hline Productive & .58 \\
\hline Winner & .49 \\
\hline \multicolumn{2}{|l|}{ Formalism $^{\mathrm{a}}$} \\
\hline Principled & .63 \\
\hline Dependable & .67 \\
\hline Trustworthy & .82 \\
\hline Honest & .67 \\
\hline Noted for integrity & .66 \\
\hline Law abiding & .35 \\
\hline \multicolumn{2}{|l|}{ Internalization ${ }^{\mathrm{b}}$} \\
\hline $\begin{array}{l}\text { It would make me feel good to be a person who has these } \\
\text { characteristics. }\end{array}$ & .84 \\
\hline $\begin{array}{l}\text { Being someone who has these characteristics is an important } \\
\text { part of who I am. }\end{array}$ & .87 \\
\hline $\begin{array}{l}\text { I would be ashamed to be a person who has these } \\
\text { characteristics, (reverse scored) }\end{array}$ & .54 \\
\hline I strongly desire to have these characteristics. & .72 \\
\hline \multicolumn{2}{|l|}{ Symbolization $^{\mathrm{b}}$} \\
\hline $\begin{array}{l}\text { I often wear clothes that identify me as having these } \\
\text { characteristics. }\end{array}$ & .60 \\
\hline $\begin{array}{l}\text { The types of things I do in my spare time (e.g., hobbies) } \\
\text { clearly identify me as having these characteristics. }\end{array}$ & .80 \\
\hline $\begin{array}{l}\text { The kinds of books and magazines that I read identify me as } \\
\text { having these characteristics. }\end{array}$ & .67 \\
\hline $\begin{array}{l}\text { The fact that I have these characteristics is communicated to } \\
\text { others by my membership in certain organizations. }\end{array}$ & .81 \\
\hline $\begin{array}{l}\text { I am actively involved in activities that communicate to } \\
\text { others that I have these characteristics. }\end{array}$ & .78 \\
\hline
\end{tabular}

Note. $\quad N=226$. Standardized factor loadings are reported.

${ }^{a}$ Brady and Wheeler (1996). ${ }^{\mathrm{b}}$ Aquino and Reed (2002) sirable Rounding scale $(\alpha=.78)$ and included this measure as a control.

\section{Results}

Table 2 provides the means, standard deviations, and correlations of the variables. With regard to the raw data, all but 10 participants $(4.4 \%)$ reported having participated in at least one of the charitable giving behaviors. More than $91 \%$ of the students reported having committed at least 1 of the 13 cheating behaviors while in college. More than $55 \%$ of the students reported that they had said nothing when they had benefited from an instructor's grading error, nearly $50 \%$ reported having inappropriately collaborated on an individual assignment, and nearly $42 \%$ indicated that they had copied from another student during a test. Thus, just as previous research indicated (McCabe \& Treviño, 1993, 1996), the data revealed that cheating was a common occurrence among this population.

To test each hypothesis, we centered the independent variables and created two sets of linear regression models, one for charitable giving and one for cheating (Aiken \& West, 1991). We investigated each model in four stages. First, we entered the control variable. Second, we entered the moral identity variables, internalization and symbolization. Next, we included the moral judgment variables, consequentialism and formalism. Finally, we included the interactions of internalization and symbolization with consequentialism and formalism.

With regard to Hypothesis 1, we argued that, in the context of a moral issue high in social consensus, internalization and symbolization would positively influence moral behavior. Table 3 shows that symbolization positively influenced charitable giving even after consequentialism, formalism, and their interactions with moral identity were entered into the equation. No other relationships were significant, and none of the other variables approached the effect size of symbolization (.03). These results support the main argument of Hypothesis 1: In a situation of high social consensus, moral identity directly influenced moral behavior.

Table 4 shows the results related to Hypotheses $2 \mathrm{a}$ and $2 \mathrm{~b}$. Regarding a moral behavior about which social consensus was not high (cheating), internalization and symbolization did not influence behavior, but both consequentialism and formalism influenced moral behavior in the directions expected, with small to medium effect sizes (.03 and .06, respectively). Moreover, the change in squared multiple correlation values $\left(\Delta R^{2}=.08\right)$ indicated a significant $(p=.00)$ improvement in model fit. These findings support Hypotheses $2 \mathrm{a}$ and $2 \mathrm{~b}$. Hypotheses $3 \mathrm{a}$ and $3 \mathrm{~b}$ stated that moral identity would interact with consequentialism and formalism to produce a behavior consistent with each framework. The interaction effect of internalization and consequentialism was positive and significant, and the interaction effect of internalization and formalism was negative and significant. Whereas the change in squared multiple correlation from Regression Model 3 to Model 4 was moderately significant $(p=.08)$, both of the significant interaction effects demonstrated modest effect sizes $(.04, .03)$. Representations of the interaction effects are presented in Figures 2 and 3, respectively. Formalistic ideals present an argument that cheating is immoral, and when formalism was coupled with the motivational force of a moral identity, cheating was at its lowest levels (the formalistic solution; see Figure 3). By the same token, 
Table 2

Study 1: Means, Standard Deviations, and Correlation Matrix of Research Variables

\begin{tabular}{|c|c|c|c|c|c|c|c|c|c|}
\hline Variable & $M$ & $S D$ & 1 & 2 & 3 & 4 & 5 & 6 & 7 \\
\hline 1. Internalization (moral identity) & 6.17 & 0.88 & - & & & & & & \\
\hline 2. Symbolization (moral identity) & 4.13 & 1.17 & $.25^{* *}$ & - & & & & & \\
\hline 3. Consequentialism (moral judgment) & 5.41 & 0.78 & $.20^{* * *}$ & .11 & - & & & & \\
\hline 4. Formalism (moral judgment) & 5.96 & 0.71 & $.52^{* *}$ & $.17^{*}$ & $.42^{* *}$ & - & & & \\
\hline 5. Social desirability & 0.22 & 0.13 & $.20^{* *}$ & -.01 & $.18^{* *}$ & $26^{* * *}$ & - & & \\
\hline 6. Charitable giving & 2.50 & 0.78 & .11 & .22 & .02 & .05 & .04 & - & \\
\hline 7. Cheating & 1.42 & 0.31 & .01 & .09 & .06 & $-.22^{* *}$ & $-.25^{* *}$ & .11 & - \\
\hline
\end{tabular}

Note. $N=226$.

${ }^{*} p \leq .05 . \quad{ }^{* *} p \leq .01$, two-tailed.

consequentialism provides a counterargument that suggests that, because of its great benefits and lack of harm, cheating can be considered a moral alternative. As Figure 2 indicates, the consequentialistic framework interacted with a moral identity such that the more consequentialistic an individual was and the stronger was his or her moral identity, the more cheating occurred (the consequentialistic solution). These results support Hypotheses $3 \mathrm{a}$ and $3 \mathrm{~b}$, as they relate to internalization. The interaction effects involving symbolization were not significant.

\section{Discussion}

The results of Study 1 provide support for our main arguments. For a moral issue about which social consensus was high, moral identity positively influenced moral behavior. That is, symbolization positively influenced charitable giving. When social consensus was not high (cheating) and it was unclear which behavior was the moral behavior, moral judgments exerted a main-effect influence on moral behavior and interacted with internalization such that individuals with the strongest moral identity were the most or least egregious of offenders, depending on their moral judgments.
These results provide evidence of the independent effects of moral judgment and moral identity and the interaction effect of the two.

We recognize that because Study 1 was conducted in an academic setting and focused on a context-specific moral behavior (cheating), the results might not be fully generalizable to managers. Therefore, we conducted a second study with the intention of establishing the generalizability of the results related to moral issues that do not involve high social consensus.

\section{Study 2: A Survey of Managers}

\section{Method}

\section{Sample}

Participants were 292 managers employed in a variety of organizations and industries. A majority of the respondents were female $(57.2 \%)$, and most were Caucasian $(84.5 \%)$. Other respondents indicated that they were Asian (6.9\%), African American (3.4\%), Hispanic $(1.2 \%)$, or of other ethnicities (4.0\%). Most $(64.8 \%)$ respondents were between 31 and 50 years old, $20 \%$ were younger than 30 , and $2.1 \%$ were more than 60 years old.

Table 3

Study 1 Test Results: The Effects of Moral Judgment and Moral Identity on Charitable Giving

\begin{tabular}{|c|c|c|c|c|c|c|c|}
\hline \multirow[b]{2}{*}{ Variable } & \multirow[b]{2}{*}{ Model $1 B$} & \multirow[b]{2}{*}{ Model $2 B$} & \multirow[b]{2}{*}{ Model $3 B$} & \multicolumn{4}{|c|}{ Model 4} \\
\hline & & & & $B$ & $S E$ & $\eta_{p}^{2}$ & $95 \% \mathrm{CI}$ \\
\hline Constant & $2.44^{* *}$ & $2.45^{* *}$ & $2.45^{* * *}$ & $2.43^{* * *}$ & 0.10 & .08 & $2.23,2.63$ \\
\hline Social desirability & 0.26 & 0.22 & 0.25 & 0.18 & 0.42 & .00 & $-0.64,1.00$ \\
\hline Internalization (moral identity) & & 0.04 & 0.05 & 0.05 & 0.07 & .00 & $-0.09,0.20$ \\
\hline Symbolization (moral identity) & & $0.14^{* *}$ & $0.14^{* *}$ & $0.11^{* *}$ & 0.05 & .03 & $0.02,0.20$ \\
\hline Consequentialism (moral judgment) & & & -0.00 & 0.04 & 0.08 & .01 & $-0.11,0.19$ \\
\hline Formalism (moral judgment) & & & -0.03 & 0.01 & 0.10 & .00 & $-0.18,0.21$ \\
\hline Internalization $\times$ Consequentialism & & & & 0.04 & 0.08 & .00 & $-0.13,0.20$ \\
\hline Internalization $\times$ Formalism & & & & 0.04 & 0.08 & .00 & $-0.12,0.19$ \\
\hline Symbolization $\times$ Consequentialism & & & & 0.10 & 0.06 & .01 & $-0.02,0.23$ \\
\hline Symbolization $\times$ Formalism & & & & 0.01 & 0.06 & .00 & $-0.12,0.14$ \\
\hline$R^{2}$ & .00 & .05 & .05 & .08 & & & \\
\hline Adjusted $R^{2}$ & .00 & .04 & .04 & .04 & & & \\
\hline$F$ & 0.44 & $4.16^{* *}$ & $2.50^{* *}$ & $2.07^{* * *}$ & & & \\
\hline$\Delta R^{2}$ & & $.05^{* * *}$ & .00 & .03 & & & \\
\hline$\Delta F$ & & $6.01^{* *}$ & 0.07 & 1.49 & & & \\
\hline
\end{tabular}

Note. $\quad N=226 . d f=225$ for all models. Unstandardized regression coefficients are shown. CI $=$ confidence interval

${ }^{* * *} p \leq .01$, one-tailed. 
Table 4

Study 1 Test Results: The Effects of Moral Judgment and Moral Identity on Cheating

\begin{tabular}{|c|c|c|c|c|c|c|c|}
\hline \multirow[b]{2}{*}{ Variable } & \multirow[b]{2}{*}{ Model $1 B$} & \multirow[b]{2}{*}{ Model $2 B$} & \multirow[b]{2}{*}{ Model $3 B$} & \multicolumn{4}{|c|}{ Model 4} \\
\hline & & & & $B$ & $S E$ & $\eta_{\mathrm{p}}^{2}$ & $95 \% \mathrm{CI}$ \\
\hline Constant & $1.55^{* *}$ & $1.55^{* *}$ & $1.55^{* *}$ & $1.55^{* *}$ & 0.04 & .19 & $1.47,1.62$ \\
\hline Social desirability & $0.60^{* *}$ & $-0.62^{* * *}$ & $-0.55^{\text {** }}$ & $-0.49^{* *}$ & 0.16 & .04 & $-0.80,-0.17$ \\
\hline Internalization (moral identity) & & 0.01 & $0.06^{*}$ & 0.04 & 0.03 & .01 & $-0.01,0.10$ \\
\hline Symbolization (moral identity) & & 0.02 & 0.02 & 0.02 & 0.02 & .00 & $-0.02,0.05$ \\
\hline Consequentialism (moral judgment) & & & $0.08^{* *}$ & $0.08^{* *}$ & 0.03 & .03 & $0.02,0.13$ \\
\hline Formalism (moral judgment) & & & $-0.15^{* *}$ & $-0.14^{* *}$ & 0.04 & .06 & $-0.21,-0.06$ \\
\hline Internalization $\times$ Consequentialism & & & & $0.09^{* *}$ & 0.03 & .04 & $0.03,0.15$ \\
\hline Internalization $\times$ Formalism & & & & $-0.07^{*}$ & 0.03 & .03 & $-0.13,-0.01$ \\
\hline Symbolization $\times$ Consequentialism & & & & -0.01 & 0.02 & .00 & $-0.06,0.04$ \\
\hline Symbolization $\times$ Formalism & & & & 0.02 & 0.02 & .00 & $-0.03,0.07$ \\
\hline$R^{2}$ & .06 & .07 & .16 & .19 & & & \\
\hline Adjusted $R^{2}$ & .06 & .06 & .14 & .15 & & & \\
\hline$F$ & $15.13^{* *}$ & $5.76^{* *}$ & $8.10^{* * *}$ & $5.52^{* *}$ & & & \\
\hline$\Delta R^{2}$ & & .01 & $.08^{* * *}$ & $.03^{\dagger}$ & & & \\
\hline$\Delta F$ & & 1.07 & $10.84^{* *}$ & $2.10^{\dagger}$ & & & \\
\hline
\end{tabular}

Note. $\quad N=226 . d f=225$ for all models. Unstandardized regression coefficients are shown. $\mathrm{CI}=$ confidence interval.

${ }^{\dagger} p<.10 .{ }^{*} p \leq .05 .{ }^{* *} p \leq .01$, one-tailed.

\section{Procedure}

The instrument was an online survey. Participants were recruited from two e-mail lists. The first list was a standing panel of participants created as a resource for social scientific research (see "The StudyResponse Project," n.d., for details). The second list was a master's of business administration alumni mailing list from a large West Coast university. With the assistance of list administrators, we sent a recruitment e-mail to approximately 2,500 managers inviting them to participate anonymously in the secure online study. A reminder e-mail was sent 1 week later. The response rate was typical for a Web survey conducted under these conditions (Cook, Heath, \& Thompson, 2000). Nevertheless, we compared responses for the two dependent variables across the first 50 respondents and the last 50 respondents and found no

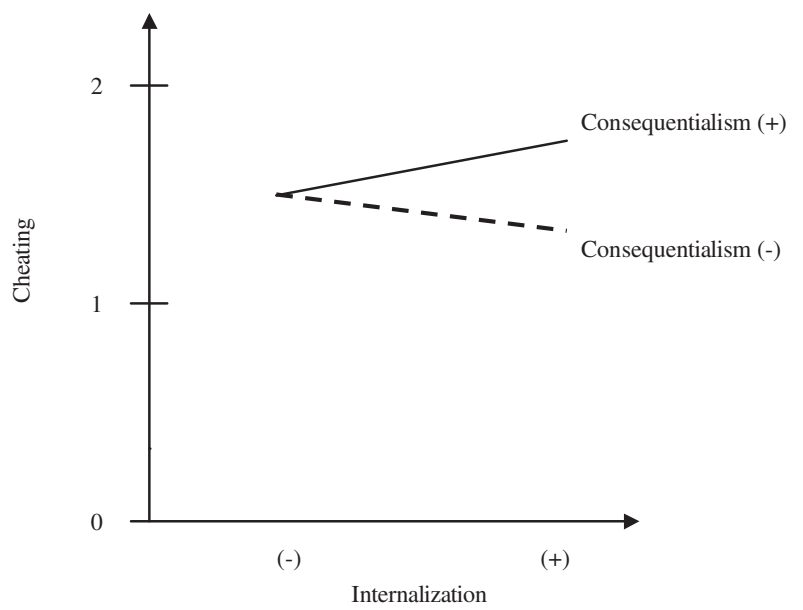

Figure 2. The interaction of internalization and consequentialism on cheating. Cheating was measured with a scale from $1=$ never to $4=$ many times. statistical differences between the two groups- $t(49)=0.48, p=$ $.63 ; t(49)=0.21, p=.83$, respectively-a finding that suggests there were no trends in the responses and thus no systematic sampling error (Dilman, 1978). In addition, there were no significant differences between the respondents of the two e-mail lists.

\section{Measures}

Dependent variable-ethical behavior. We identified two moral behavior measures that potentially did not involve high social consensus. First, Newstrom and Ruch's (1975) scale of ethical behavior asks respondents to indicate on a Likert-type scale $(1=$ never, $7=$ frequently $)$ the extent to which they had engaged in each of 17 behaviors (e.g., using company services for personal use, calling in sick to take a day off, not reporting others' violations of company policies and rules). Newstrom and Ruch consid-

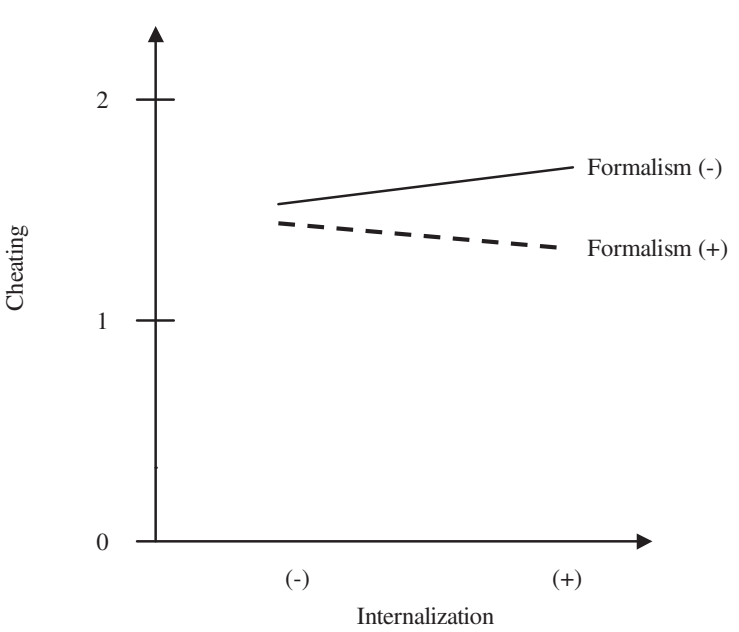

Figure 3. The interaction of internalization and formalism on cheating. Cheating was measured with a scale from $1=$ never to $4=$ many times. 
ered the 17 behaviors to be unequivocally immoral workplace practices, but many of these behaviors can be morally ambiguous. For example, many companies allow their employees to use some services for personal use and tacitly expect their employees to use sick days at their own discretion. Under such conditions, those behaviors are not necessarily immoral. Similarly, one can imagine situations in which reporting a violation might not necessarily be the right thing to do (e.g., a new employee unknowingly violates a minor, outdated rule and is privately informed of the violation). Therefore, we theorized that there was room for disagreement about the absolute morality of these behaviors. The scale demonstrated high reliability $(\alpha=.90)$.

Dependent variable - vignette response. As a second measure of a moral behavior not high in social consensus, we presented respondents with a vignette created for this research (and listed with a series of other business-related vignettes) and asked the participants to indicate from among four choices what they would do in that situation. The vignette was patterned after existing vignettes used in research on consequentialism and formalism (e.g., Brady \& Wheeler, 1996; Fritzsche \& Becker, 1984) and followed established guidelines for the use of vignettes in ethics research (Weber, 1990). The vignette used in this research was as follows:

It's Friday. At noon, your current intern comes into your office to tell you that she has finished her project and has nothing to do until the quarterly reports come in on Monday. You are not surprised. She is an excellent worker. She completes every project flawlessly far ahead of any deadline, and you definitely want to hire her when the internship is over. You know that she has plans for the weekend and would probably like to leave early, but she is an hourly employee and needs the money. You guess that you can probably find about 2 hours of "busy work" for her, but you'll never be able to keep her busy all afternoon. Of the following, which are you most likely to do?

Four alternatives were presented: (a) give the intern the rest of the day off with pay, (b) have her finish the busy work and then give her the rest of the day off with pay, (c) have her finish the busy work and then give her the option of taking the rest of the day off without pay, and (d) have her finish the busy work and then "find something else to do (there's always something else to do)." These responses varied in the extent that they sought the greatest benefit for the intern while adhering to the rules of the workplace. Thus, they created a continuum of behaviors that ranged from the very consequentialistic (Option a) to the very formalistic (Option d). Brady and Wheeler (1996) used a multiple-response format to demonstrate that individuals can hold strong preferences for both consequentialistic and formalistic ideals, but the single-response format reduced competing preferences to a single scalable behavior (e.g., Fritzsche \& Becker, 1984).

It was presumed that because the ethical behavior measure (Newstrom \& Ruch, 1975) and the vignette involved competing objectives and obligations, social consensus regarding the moral alternatives would not be high. These assumptions were tested with a second sample. Approximately 150 managers who regularly participated on a career management Listserv were contacted via a Listserv member and invited to complete the validation study. Forty people completed this short, Web-based instrument (age: $M$ = 43.7, $S D=12.9$; tenure: $M=13.0$ years, $S D=10.3 ; 30 \%$ male). As a baseline measure, respondents were presented with the list of charitable giving behaviors from Study 1 and asked, "In your opinion, to what extent do business managers (in general) agree that the following behaviors are morally good things to do?" Social consensus was measured with one item on a 5-point Likerttype scale ranging from 1 (there is a great deal of disagreement) to 5 (there is a great deal of agreement). The respondents were then presented the behaviors from Newstrom and Ruch's (1975) scale of ethical behavior and asked, "In your opinion, to what extent do business managers (in general) agree that these behaviors are morally wrong?" Finally, the respondents were presented with the vignette and asked, "In your opinion, to what extent would business managers (in general) agree about what is the morally right thing to do in this situation?" In each case, the 5-point scale of agreement followed.

Results of this validation study suggest that charitable giving was considered an issue high in social consensus $(M=4.53, S D=$ 0.75). Paired sample $t$ tests confirmed that the respondents believed that Newstrom and Ruch's (1975) scale of ethical behavior $(M=3.80, S D=1.14)$ and the vignette $(M=2.60, S D=0.60)$ both involved behaviors with significantly less social consensus than the act of charitable giving, $t(39)=3.47, p<.01, t(39)=$ 9.30, $p<.01$, respectively. Analysis revealed large effect sizes ( $d=0.76$ and 2.24 , respectively). These results indicate that the scale of ethical behavior and the vignette involved issues not high in social consensus. In addition, as expected, the respondents believed that the vignette involved an issue with less social consensus than the ethical behavior scale, $t(39)=6.10, p<.01$. In this case, the effect size $(d=1.14)$ was large. This indicated that even though both measures were not high in social consensus, they involved significantly different levels of social consensus.

Independent and control variables. We measured consequentialism, formalism, internalization, symbolization, and social desirability with the same scales used in Study 1. In this study, all five internalization items were included. The measures were analyzed according to the same procedure as that employed in Study 1 ; the analysis generated nearly identical results (e.g., consequentialism, $\alpha=.84$; formalism, $\alpha=.83$; internalization, $\alpha=.79$; symbolization, $\alpha=.87$; social desirability, $\alpha=.83$ ).

\section{Results}

The means, standard deviations, and correlations of these variables are presented in Table 5. Results of the regression analyses are presented in Tables 6 and 7. In the case of Newstrom and Ruch's (1975) measure of ethical behavior, formalism had a significant main effect, as predicted by Hypothesis 2b. Although consequentialism did not exert a main effect on ethical behavior (Hypothesis 2a) nor interact with moral identity to shape ethical behavior (Hypothesis 3a), the interaction effects of formalism and internalization and of formalism and symbolization significantly influenced ethical behavior. Moreover, including the interaction effects significantly improved the final regression model's fit $\left(\Delta R^{2}=.07, p=.00\right)$. Figures 4 and 5 provide graphical representations of these interactions. As predicted, ethical behavior was greatest (at its lowest value) when formalism and internalization were high and when formalism and symbolization were high. These results support Hypothesis $3 b$.

With regard to the vignette, the main effect of consequentialism was not significant, but formalism significantly influenced moral 
Table 5

Study 2: Means, Standard Deviations, and Correlation Matrix of Research Variables

\begin{tabular}{|c|c|c|c|c|c|c|c|c|c|}
\hline Variable & $M$ & $S D$ & 1 & 2 & 3 & 4 & 5 & 6 & 7 \\
\hline $\begin{array}{l}\text { 1. Internalization } \\
\text { (moral identity) }\end{array}$ & 6.24 & 0.88 & - & & & & & & \\
\hline $\begin{array}{l}\text { 2. Symbolization } \\
\text { (moral identity) }\end{array}$ & 4.27 & 1.35 & $.28^{* *}$ & - & & & & & \\
\hline $\begin{array}{l}\text { 3. Consequentialism } \\
\text { (moral judgment) }\end{array}$ & 5.48 & 0.84 & $.24^{* *}$ & $.26^{* *}$ & - & & & & \\
\hline $\begin{array}{l}\text { 4. Formalism (moral } \\
\text { judgment) }\end{array}$ & 6.25 & 0.69 & $.43^{* *}$ & $.26^{* *}$ & $.57^{* *}$ & - & & & \\
\hline 5. Social desirability & 10.10 & 7.27 & $.24^{* * *}$ & $.22^{* *}$ & $.27^{* * *}$ & $.25^{* *}$ & - & & \\
\hline 6. Ethical behavior ${ }^{\mathrm{a}}$ & 1.96 & 0.74 & $-.30^{* * *}$ & -.03 & $-.17^{* * *}$ & $-.29^{* *}$ & $-.39^{* *}$ & - & \\
\hline 7. Vignette response & 2.53 & 0.87 & -.05 & .06 & .09 & .12 & -.02 & -.05 & - \\
\hline
\end{tabular}

Note. $\quad N=290$.

${ }^{a}$ Newstrom and Ruch (1975). Low values indicate more ethical behavior.

*** $p \leq .01$, two-tailed.

behavior in the direction expected for a vignette such as this one (Brady \& Wheeler, 1996). This result provides support for Hypothesis $2 \mathrm{~b}$. As Hypotheses $3 \mathrm{a}$ and $3 \mathrm{~b}$ predicted, the interaction between internalization and consequentialism was negative and significant, the interaction between internalization and formalism was positive and significant, and the interaction effects were significant additions to the overall regression model $\left(\Delta R^{2}=.05\right.$, $p=.01$ ). Figures 6 and 7 provide graphical representations of the interaction effects. These figures demonstrate that consequentialists with a strong moral identity were most inclined toward the most consequentialistic outcome, whereas formalists with a strong moral identity were the most likely to choose the most formalistic behavior-having the intern work the entire afternoon. In each case, internalization interacted with judgment to lead to the most extreme alternatives. These results provide support for Hypotheses $3 \mathrm{a}$ and $3 \mathrm{~b}$ as they relate to internalization.

\section{Discussion}

The results of Study 2 provide additional evidence that supports our arguments related to moral issues not high in social consensus. In the case of Newstrom and Ruch's (1975) measure of ethical behavior, formalism interacted with internalization and symbolization as expected, but consequentialism did not. We suspect that these mixed results were due to the fact that the measure, while not high in social consensus, was not as low in social consensus as the other measures. Apparently, there was enough moral ambiguity in this measure to foster one form of interaction, but the counterargument was not powerful enough to create an equivalent effect in the opposite direction. With regard to the vignette, the results indicate that internalization interacted with both consequentialism and formalism to lead an individual to the most extreme or idyllic of solutions. In this case, the consequentialists with a strong moral

Table 6

Study 2 Test Results: The Effects of Moral Judgment and Moral Identity on Ethical Behavior

\begin{tabular}{|c|c|c|c|c|c|c|c|}
\hline \multirow[b]{2}{*}{ Variable } & \multirow[b]{2}{*}{ Model $1 B$} & \multirow[b]{2}{*}{ Model $2 B$} & \multirow[b]{2}{*}{ Model $3 B$} & \multicolumn{4}{|c|}{ Model 4} \\
\hline & & & & $B$ & $S E$ & $\eta_{p}^{2}$ & $95 \%$ CI \\
\hline Constant & $2.35^{* * *}$ & $2.32^{* *}$ & $2.30^{* * *}$ & $2.26^{* *}$ & 0.07 & .82 & $2.13,2.39$ \\
\hline Social desirability & $-0.04^{* *}$ & $-0.04^{* *}$ & $-0.03^{* * *}$ & $-0.03^{* *}$ & 0.01 & .08 & $-0.04,-0.02$ \\
\hline Internalization (moral identity) & & $-0.21^{* *}$ & $-0.16^{* *}$ & $-0.16^{* *}$ & 0.05 & .04 & $-0.25,-0.06$ \\
\hline Symbolization (moral identity) & & $-.06^{* *}$ & $0.07^{* * *}$ & $0.09^{* *}$ & 0.03 & .03 & $0.03,0.15$ \\
\hline Consequentialism (moral judgment) & & & 0.01 & 0.01 & 0.05 & .00 & $-0.10,0.11$ \\
\hline Formalism (moral judgment) & & & $-0.18^{* *}$ & $-0.23^{* *}$ & 0.08 & .03 & $-0.38,-0.07$ \\
\hline Internalization $\times$ Consequentialism & & & & -0.07 & 0.06 & .01 & $-0.19,0.05$ \\
\hline Internalization $\times$ Formalism & & & & $0.18^{* *}$ & 0.06 & .03 & $0.06,0.31$ \\
\hline Symbolization $\times$ Consequentialism & & & & 0.03 & 0.04 & .00 & $-0.05,0.10$ \\
\hline Symbolization $\times$ Formalism & & & & $-0.22^{* *}$ & 0.05 & .06 & $-0.32,-0.12$ \\
\hline$R^{2}$ & .15 & .21 & .23 & .30 & & & \\
\hline Adjusted $R^{2}$ & .15 & .20 & .22 & .27 & & & \\
\hline$F$ & $51.28^{* *}$ & $25.14^{* *}$ & $16.83^{* * *}$ & $13.12^{* * *}$ & & & \\
\hline$\Delta R^{2}$ & & $.06^{* *}$ & $.02^{*}$ & $.07^{* * *}$ & & & \\
\hline $\overrightarrow{\Delta F}$ & & $10.40^{* *}$ & $3.66^{*}$ & $6.78^{* *}$ & & & \\
\hline
\end{tabular}

Note. $\quad N=290 . d f=289$ for all models. Unstandardized regression coefficients are shown. $\mathrm{CI}=$ confidence interval. The results are based on Newstrom and Ruch (1975); low values indicate more ethical behavior.

${ }^{*} p \leq .05 .{ }^{* *} p \leq .01$, one-tailed. 


\begin{tabular}{|c|c|c|c|c|c|c|c|}
\hline \multirow[b]{2}{*}{ Variable } & \multirow[b]{2}{*}{ Model $1 B$} & \multirow[b]{2}{*}{ Model $2 B$} & \multirow[b]{2}{*}{ Model $3 B$} & \multicolumn{4}{|c|}{ Model 4} \\
\hline & & & & $B$ & $S E$ & $\eta_{p}^{2}$ & $95 \% \mathrm{CI}$ \\
\hline Constant & $2.55^{* *}$ & $2.55^{* *}$ & $2.59^{* *}$ & $2.54^{* *}$ & 0.13 & .63 & $2.29,2.80$ \\
\hline Social desirability & 0.00 & 0.00 & -0.01 & 0.00 & 0.01 & .00 & $-0.02,0.02$ \\
\hline Internalization (moral identity) & & -0.06 & $-0.13^{*}$ & -0.10 & 0.07 & .01 & $-0.25,0.05$ \\
\hline Symbolization (moral identity) & & 0.05 & 0.03 & 0.03 & 0.04 & .00 & $-0.06,0.11$ \\
\hline Consequentialism (moral judgment) & & & 0.02 & 0.05 & 0.08 & .00 & $-0.12,0.22$ \\
\hline Formalism (moral judgment) & & & $0.21^{*}$ & $0.27^{*}$ & 0.12 & .02 & $0.03,0.52$ \\
\hline Internalization $\times$ Consequentialism & & & & $-0.18^{*}$ & 0.10 & .02 & $-0.36,0.01$ \\
\hline Internalization $\times$ Formalism & & & & $0.28^{* *}$ & 0.10 & .03 & $0.08,0.49$ \\
\hline Symbolization $\times$ Consequentialism & & & & -0.09 & 0.06 & .01 & $-0.20,0.02$ \\
\hline Symbolization $\times$ Formalism & & & & -0.01 & 0.07 & .00 & $-0.15,0.14$ \\
\hline$R^{2}$ & .00 & .01 & .03 & .08 & & & \\
\hline Adjusted $R^{2}$ & .00 & .00 & .01 & .04 & & & \\
\hline$F$ & 0.05 & 0.64 & 1.56 & $2.23^{*}$ & & & \\
\hline$\Delta R^{2}$ & & .01 & $.02^{*}$ & $.05^{* *}$ & & & \\
\hline$\Delta F$ & & 0.94 & $2.90^{*}$ & $3.01^{* *}$ & & & \\
\hline
\end{tabular}

Note. $\quad N=290 . d f=289$ for all models. Unstandardized regression coefficients are shown. CI $=$ confidence interval.

${ }^{*} p \leq .05$. ${ }^{* *} p \leq .01$, one-tailed.

identity acted in the most consequentialistic manner, and the formalist with a strong moral identity acted in the most formalistic manner. As the vignette represented a situation with the lowest levels of social consensus and thus most aptly reflected the classic moral dilemma, these findings are perhaps the most telling of this study.

Study 2 provides evidence of the generalizability of our findings. The sample in Study 2 was representative of a much larger general population of managers. The issues that they considered (an established scale of day-to-day moral behaviors and a workplace vignette) covered a spectrum of workplace behaviors, ranging from the benign to the serious. As a result, we suggest that the findings of the two studies are relevant for both students and managers in a wide variety of settings and circumstances.

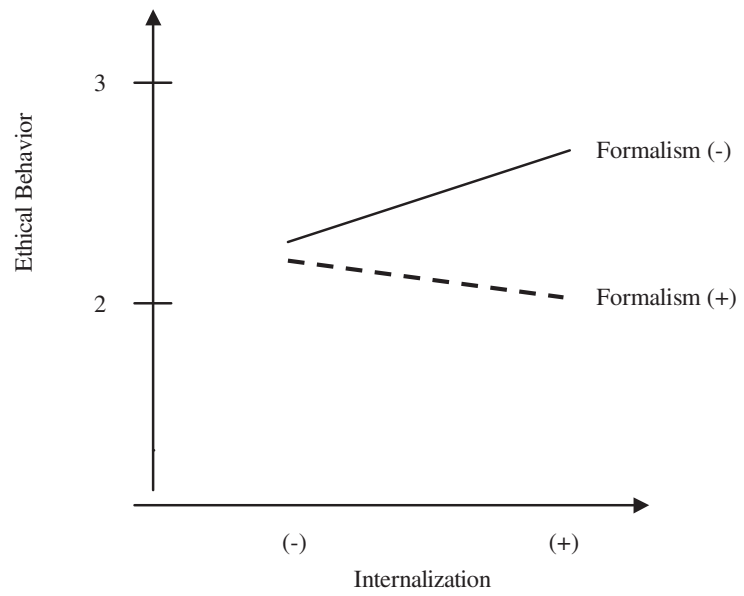

Figure 4. The interaction of internalization and formalism on ethical behavior (Newstrom \& Ruch, 1975). Low values indicate more ethical behavior.

\section{General Discussion}

Our objective in this research was to test arguments rooted in cognitive developmental and identity theories, particularly social identity theory, that moral judgment and moral identity independently influence moral behavior and, when social consensus about the behavior is not high, interact to influence moral behavior. Study 1 demonstrates that moral identity influenced moral behaviors high in social consensus independently of the influence of moral judgments (Hypothesis 1). Studies 1 and 2 both demonstrate that when social consensus was not high, moral judgments influenced moral behavior even after the effects of moral identity were accounted for (Hypotheses $2 \mathrm{a}$ and $2 \mathrm{~b}$ ). Further, the results of both studies suggest that in situations in which social consensus is not high, the moral status of a behavior must be determined by an act

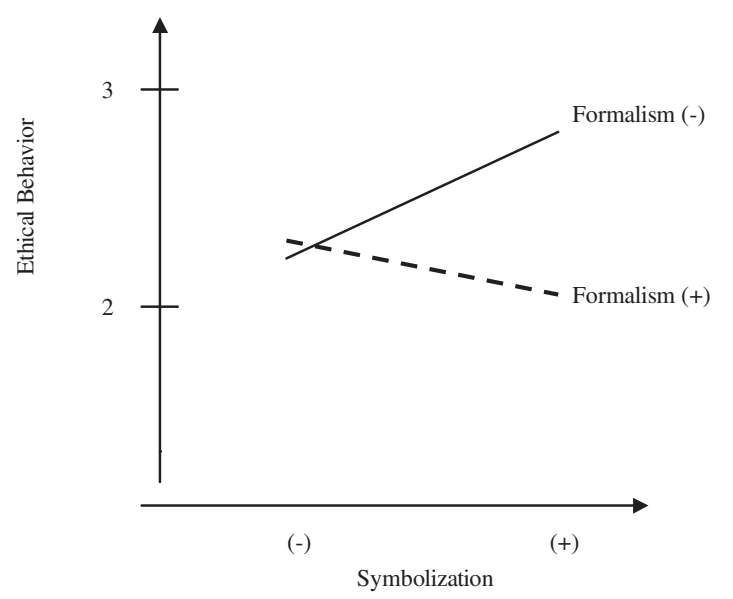

Figure 5. The interaction of symbolization and formalism on ethical behavior (Newstrom \& Ruch, 1975). Low values indicate more ethical behavior. 


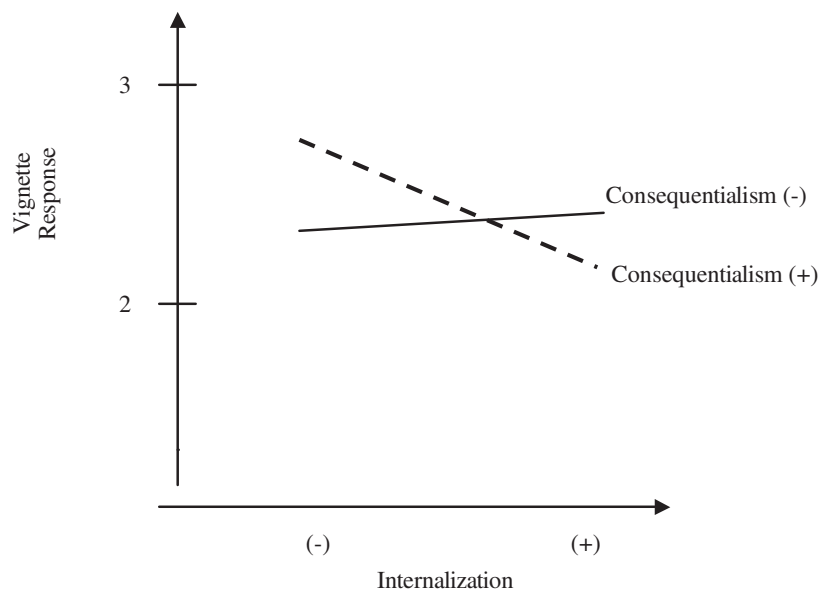

Figure 6. The interaction of internalization and consequentialism on vignette response. Low values indicate more consequentialistic behavior. High values indicate more formalistic behavior.

of moral judgment; therefore, moral identity was motivational to the extent that it had a direction to motivate (Hypotheses $3 \mathrm{a}$ and $3 b)$. Generally speaking, these results confirm that it is appropriate to consider a combined approach, an approach that considers and incorporates moral judgments, moral identity, and the interaction of the two, in studying moral behavior.

With regard to specific findings, these studies have generated sufficient evidence to assert that moral identity affects moral behavior, but these same results also indicate that future research must pay greater attention to the unique properties and effects of the individual dimensions of moral identity-namely, internalization and symbolization. Indeed, at least three different sets of results indicate unique properties of each dimension. First, internalization demonstrated much more robust moderating effects than did symbolization. As we discussed earlier, internalization refers to the individual's self conception, and, as such, it seems much more personal, more reflective, and more representative of concepts generally associated with moral motivation (i.e., fortitude, courage) than does symbolization. From a traditional or anecdotal perspective, the strength to act morally is thought to originate from within (Rest, 1986), and in our view an internalized moral identity seems consistent with that characterization, whereas symbolization does not.

Second, although neither internalization nor symbolization exerted a main effect on cheating or the vignette response, internalization was positively related to Newstrom and Ruch's (1975) measure of ethical behavior, while symbolization was negatively related. Results from the validating sample indicate that this scale involved a moderate degree of social consensus, and therefore it is not surprising that internalization was positively associated with moral behavior (as would be expected in a situation involving high social consensus). The results regarding symbolization, however, are surprising. Apparently the internal aspects of moral identity reduced unethical behavior, while the external aspects increased it. Future research might explore how the different aspects of a moral identity could have such contradictory effects.

Finally, symbolization played an important role in charitable giving, but internalization did not. These results are, in some respects, inconsistent with previous research, but, in truth, this outcome is entirely consistent with the behavioral aspects of symbolization and internalization as defined by Aquino and Reed (2002). Referencing Erikson (1964), they suggested that symbolization reflects the degree to which an individual's moral identity is expressed through action. Charitable giving is a set of specific behaviors that provides opportunities for the individual to symbolize his or her identity. Thus, it is absolutely consistent with theory to suggest that individuals symbolize their moral traits through such behaviors as volunteering, donating items to the needy, and making donations to charities. All of these findings point to the same general conclusion: The next step in exploring the concept of moral identity is to identify more clearly the unique qualities of internalization and symbolization.

Our conclusions regarding moral identity and its dimensions notwithstanding, we believe that the results regarding the general interaction effect between moral judgment and moral identity are the most significant aspects of this research. Not only do these results provide evidence of the need for and the legitimacy of an integrated approach to the study of moral behavior, but they also hint at something more. The general interaction effect of moral judgment and moral identity epitomizes the complexity that is unique to morality and moral behavior. At one moment, morality is the confluence of a detached society and an engaged individual. Incorporating moral judgments and moral identity into one factor effectively brings together society and the individual, the objective and the subjective, and the rational and the affective in one stroke (Bergman, 2002). Accordingly, the interaction effect supports both an integrated approach to the study of moral behavior and the much grander, integrated view of moral behavior. Perhaps future research can focus attention on the exact nature and effects of the interaction between moral judgments and moral identity to shed greater light on the larger topic of morality.

\section{Limitations}

Three limitations of this research are worth discussing here. First, this research theorizes about abstract concepts (i.e., moral

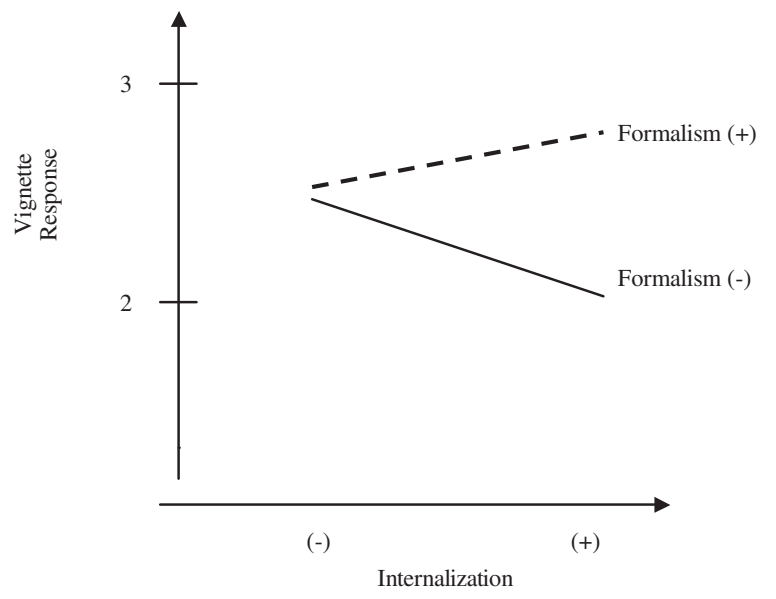

Figure 7. The interaction of internalization and formalism on vignette response. Low values indicate more consequentialistic behavior. High values indicate more formalistic behavior. 
judgment and moral identity) but relies on only one operationalization of each (consequentialism-formalism and Aquino and Reed's, 2002, moral identity construct). We acknowledge that the results of these studies might be specific to these operationalizations. Future research should explore other means for measuring moral judgment (e.g., moral development) and moral identity as additional tests of the underlying theoretical explanations.

Second, some of our measures were not ideal. Confirmatory factor analyses revealed an acceptable fit for the four-factor model of the independent variables, but a better fit would have been preferable. Similarly, the validation studies relied on single-item measures of social consensus, which could possibly distort our validation efforts. We suggest that future research utilize even more precise measures of these key constructs to reduce these kinds of concerns.

Finally, although the research used multiple measures of moral behavior to explore the generalizability of the findings, each was subject to common-method, common-source variance (Campbell $\&$ Fiske, 1959). We note that the nature of the hypotheses and the analyses partially mitigates these concerns. We hypothesized both negative and positive relationships, and many of the main effects were not significant. Given that common-method, common-source variance points to a singular directional bias, the multidirectionality and second-order nature of these results suggests that those concerns are not as significant as they might be under different conditions. Moreover, we controlled for social desirability bias, which can account for some of the effects of common method bias (Podsakoff, MacKenzie, Lee, \& Podsakoff, 2003). Nevertheless, future research might utilize different sources to measure moral behavior and/or apply other techniques (questionnaire design, latent variable analysis, etc.) to minimize these concerns (Podsakoff et al., 2003).

\section{Implications}

\section{Theoretical}

These results have substantial implications for the study of moral behavior. In particular, this research adds to the growing body of empirical research on moral identity and points toward entirely new areas of study. For example, moral identity is regularly associated with the concept of moral motivation, but moral motivation has been considered a mediator in the moral decisionmaking process. Eisenberg (1986) cited several studies focusing on moral intentions (Zuckerman \& Reis, 1978) and concluded that moral motivation has no effect on moral behavior independent of traditional cognitive processes. Our research demonstrates that moral identity does have an independent effect, but rather than shaping cognitions as moral motivation is thought to do, moral identity instead interacted with cognitions as an independent force. So even though moral identity is associated with and perhaps a source of moral motivation, these results indicate that moral identity is distinct from moral motivation. Future research should explore the unique qualities of moral identity to better distinguish moral identity from moral motivation and more completely specify the relationship between the two.

In addition, this research demonstrates that moral identity is not as "moral" as perhaps originally conceived. The tone of previous work has implied that moral identity is "good" in that it is asso- ciated with and motivates individuals toward socially desirable outcomes, such as volunteering and making charitable donations. The findings here demonstrate that this motivational force needs direction and that, without proper guidance, a moral identity can conceivably push individuals toward socially undesirable behaviors. Moral identity might thus be more motivational in nature than moral in nature. Managers and organizations should not just assume that a moral identity will necessarily translate into moral behaviors. Reynolds (2003) demonstrated that positive perceptions of the moral self among employees do not necessarily benefit the organization, and these findings confirm that general argument, so it seems prudent for managers to foresee and prepare for such outcomes.

More generally, this research supports the notion of integrating moral identity with established arguments found in cognitive development theory and, in so doing, reaffirms the value of a cognitive approach to moral behavior. Some years ago, the field awoke to its reliance on the cognitive approach and began moving toward other areas of study, perhaps at the expense of existing knowledge. The results of this research attest that while we might have perhaps overrelied on cognition in the past, we did so for good reason. As the field moves toward other areas, including identity, emotion, and intuition (Gaudine \& Thorne, 2001; Haidt, 2001; Reynolds, 2006b), this research affirms that it is wise to integrate into those new areas what research based on the cognitive perspective has already established.

\section{Practical}

In terms of practice, the research provides several insights regarding how to improve moral behavior in organizations. Given the factors considered in this study, the results indicate that organizations and their leaders have the potential to affect moral behavior in three different ways. Taken together, these behaviors increase the likelihood that individuals will be motivated to act morally and will have sufficient guidance on how to do so.

First, organizations can focus on improving individual moral judgments. Cognitive developmental theories (e.g., Kohlberg, 1984) suggest that moral development improves with formal education, a conclusion that affirms the need for formal ethics training programs in organizations. In addition, cognitive developmental theory argues that individuals develop morally when higher stages are modeled for them and when they are given opportunities to lead. This places a burden on leadership to both model sound moral judgment and delegate authority appropriately.

Second, organizations can more effectively communicate social consensus from higher sources (e.g., state and federal law) and more firmly establish social consensus within their own boundaries (e.g., gift-giving policies). Doing so would presumably reduce the need for individual moral judgment and remove some of the variance in individual behavior. Mechanisms for conveying social consensus include codes of conduct and both formal (newsletters, e-mails, etc.) and informal (speeches, conversations, etc.) information channels.

Finally, organizations can reward and encourage behaviors that are associated with the traits of a moral identity (e.g., fair, hardworking, compassionate), thereby encouraging the development of moral identities within employees. Both formal and informal systems have to be considered, and such efforts would have implica- 
tions for the identity of the entire organization. Nevertheless, the results of this research indicate that to the extent that the organization employs individuals with strong moral identities, moral behavior is likely to follow.

As an example of how these practical implications might translate in an organizational setting to facilitate change, consider how these factors might be applied to the issue of cheating. The results of this research suggest that an institution trying to reduce cheating should hold formal discussions about the rules and the negative long-term consequences associated with cheating (e.g., harm to others, possible expulsion, lack of learning), provide more information about the institution's and society's general disdain for cheating, and develop reward and punishment systems that emphasize positive moral traits. Clearly, these actions would require a coordinated program of effort, but, given the rampant levels of cheating and similar behaviors ongoing in today's higher educational settings, such an effort seems well justified.

\section{Conclusion}

Moral behavior is a complicated phenomenon that exhibits variance due to a wide variety of factors. Nevertheless, at the core of these complicated processes are fairly simple distinctions that allow individuals to make sense of their world and constitute critical levers for changing behavior. To the extent that researchers can continue to identify these constructs, whether they distinguish between self and others, the means and the ends, or other simple demarcations, we believe that useful opportunities to influence moral behavior will continue to emerge.

\section{References}

Abdolmohammadi, M., \& Sultan, J. (2002). Ethical reasoning and the use of insider information in stock trading. Journal of Business Ethics, 37, $165-173$.

Ahmed, S. A., \& Jackson, D. N. (1979). Psychographics for social policy decisions: Welfare assistance. Journal of Consumer Research, 5, 229239.

Aiken, L. S., \& West, S. G. (1991). Multiple regression: Testing and interpreting interactions. Thousand Oaks, CA: Sage.

Anderson, J. C., \& Gerbing, D. W. (1988). Structural equation modeling in practice: A review and recommended two-step approach. Psychological Bulletin, 103, 411-423.

Aquino, K., \& Reed, A., II. (2002). The self-importance of moral identity. Journal of Personality and Social Psychology, 83, 1423-1440.

Badaracco, J. L., Jr. (1997). Defining moments: When managers must choose between right and right. Boston: Harvard Business School Press.

Bentler, P. M., \& Bonett, D. G. (1980). Significance tests and goodness of fit in the analysis of covariance structures. Psychological Bulletin, 88, $588-606$.

Bergman, R. (2002). Why be moral? A conceptual model from developmental psychology. Human Development, 45, 104-124.

Bernardi, R. A., Metzger, R. L., Bruno, R. G. S., Hoogkamp, M. W., Reyes, L. E., \& Barnaby, G. H. (2004). Examining the decision process of students' cheating behavior: An empirical study. Journal of Business Ethics, 50, 397-414.

Blasi, A. (1980). Bridging moral cognition and moral action: A critical review of the literature. Psychological Bulletin, 88, 1-45.

Blasi, A. (1984). Moral identity: Its role in moral functioning. In W. Kurtines \& J. Gewirtz (Eds.), Morality, moral behavior and moral development (pp. 128-139). New York: Wiley.

Blasi, A. (1989). The integration of morality in personality. In I. E. Bilbao
(Ed.), Perspectivas acerca de cambio moral: Posibles intervenciones educativas (pp. 119-131) [Perspectives on moral change: Possible educational interventions]. San Sebastian, Spain: Servicio Editorial Universidad Del Pais Vasco.

Brady, F. N. (1985). A Janus-headed model of ethical theory: Looking two ways at business-society issues. Academy of Management Review, 10, $568-577$.

Brady, F. N., \& Wheeler, G. E. (1996). An empirical study of ethical predispositions. Journal of Business Ethics, 15, 927-941.

Browne, M. W., \& Cudeck, R. (1992). Alternative ways of assessing model fit. Sociological Methods and Research, 21, 230-258.

Callahan, D. (2004). The cheating culture: Why more Americans are doing wrong to get ahead. Orlando, FL: Harcourt Books.

Campbell, D. T., \& Fiske, D. W. (1959). Convergent and discriminant validation by the multitrait-multimethod matrix. Psychological Bulletin, $56,81-105$.

Cavanagh, G. F., \& Moberg, D. J. (1999). The virtue of courage within the organization. Research in Ethical Issues in Organizations, 1, 1-25.

Colby, A., \& Damon, W. (1992). Some do care: Contemporary lives of moral commitment. New York: Free Press.

Cook, C., Heath, F., \& Thompson, R. L. (2000). A meta-analysis of response rates in Web- or Internet-based surveys. Educational and Psychological Measurement, 60, 821-836.

Damon, W. (1984). Self-understanding and moral development from childhood to adolescence. In W. M. Kurtines \& J. L. Gewirtz (Eds.), Morality, moral behavior, and moral development (pp. 109-127). New York: Wiley.

Damon, W., \& Hart, D. (1992). Self-understanding and its role in social and moral development. In M. Bornstein \& M. Lamb (Eds.), Developmental psychology: An advanced textbook (pp. 421-458). Hillsdale, NJ: Erlbaum.

Dilman, D. (1978). Mail and telephone surveys: The total design method. New York: Wiley.

Eisenberg, N. (1986). Altruistic emotion, cognition and behavior. Hillsdale, NJ: Erlbaum.

Erikson, E. H. (1964). Insight and responsibility. New York: Norton.

Fishbein, M., \& Azjen, I. (1975). Belief, attitude, intention and behavior: An introduction to theory and research. Reading, MA: Addison-Wesley.

Ford, R. C., \& Richardson, W. D. (1994). Ethical decision making: A review of the empirical literature. Journal of Business Ethics, 13, 205221.

Forsyth, D. R. (1985). Individual differences in information integration during moral judgment. Journal of Personality and Social Psychology, 49, 264-272.

Fraedrich, J. P. (1993). The ethical behavior of retail managers. Journal of Business Ethics, 12, 207-213.

Fritzsche, D. J., \& Becker, H. (1984). Linking management behavior to ethical philosophy: An empirical investigation. Academy of Management Journal, 27, 166-175.

Gaudine, A., \& Thorne, L. (2001). Emotion and ethical decision making. Journal of Business Ethics, 31, 175-185.

Goolsby, J. R., \& Hunt, S. D. (1992). Cognitive moral development and marketing. Journal of Marketing, 56, 55-68.

Green, S. A., \& Weber, J. A. (1997). Influencing ethical development: Exposing students to the AICPA Code of Conduct. Journal of Business Ethics, 16, 777-790.

Greenberg, J. (2002). Who stole the money, and when? Individual and situational determinants of employee theft. Organizational Behavior and Human Decision Processes, 89, 985-1003.

Haidt, J. (2001). The emotional dog and its rational tail: A social intuitionist approach to moral judgment. Psychological Review, 108, 814-834.

Henle, C. A., Giacalone, R. A., \& Jurkiewicz. C. L. (2005). The role of ethical ideology in employee deviance. Journal of Business Ethics, 56, 219-230. 
Honderich, T. (Ed.). (1995). The Oxford companion to philosophy. Oxford, England: Oxford University Press.

Hu, L., \& Bentler, P. (1999). Cutoff criteria for fit indexes in covariance structure analysis: Conventional criteria versus new alternatives. Structural Equation Modeling, 6, 1-56.

Hunt, S. D., \& Vasquez-Parraga, A. Z. (1993). Organizational consequences, marketing ethics, and salesforce supervision. Journal of Marketing Research, 38, 78-90.

Jones, T. M. (1991). Ethical decision making by individuals in organizations: An issue-contingent model. Academy of Management Review, 16, 366-395.

Kant, I. (1994). Ethical philosophy (2nd ed.; J. W. Ellington, Trans.). Indianapolis, IN: Hackett Publishing. (Original work published 1785)

Kohlberg, L. (1981). The philosophy of moral development. San Francisco: Harper \& Row.

Kohlberg, L. (1984). The psychology of moral development: The nature and validity of moral stages. New York: Harper \& Row.

Kohn, M., \& Schooler, C. (1983). Work and personality: An inquiry into the impact of social satisfaction. Norwood, NJ: Ablex.

Krantz, J. H., \& Dalal, R. (2000). Validity of Web-based psychological research. In M. Birnbaum (Ed.), Psychological experiments on the Internet (pp. 35-60). San Diego, CA: Academic Press.

Laczniak, G. R., \& Inderrieden, E. J. (1987). The influence of stated organizational concern upon ethical decision making. Journal of Business Ethics, 6, 297-307.

McCabe, D. L., \& Treviño, L. K. (1993). Academic dishonesty: Honor codes and other contextual influences. Journal of Higher Education, 64, 522-538.

McCabe, D. L., \& Treviño, L. K. (1996). What we know about cheating in college: Longitudinal trends and recent developments. Change, 28, $28-34$.

McCabe, D. L., Treviño, L. K., \& Butterfield, K. (1996). The influence of collegiate and corporate codes of conduct on ethics-related behavior in the workplace. Journal of Higher Education, 2, 211-234.

Mill, J. S. (1987). Utilitarianism and other essays. New York: Penguin Classics. (Original work published 1863)

Mitchell, T. R., \& Daniels, D. (2002). Motivation. In W. C. Borman, D. R. Ilgen, \& R. J. Klimoski (Eds.), Comprehensive handbook of psychology: Vol. 12. Industrial and organizational psychology (pp. 225-254). New York: Wiley.

Moreland, C., \& Leach, M. M. (2001). The relationship between Black racial identity and moral development. Journal of Black Psychology, 27, 255-271.

Narvaez, D., Getz, I., Rest, J. R., \& Thoma, S. J. (1999). Individual moral judgment and cultural ideologies. Developmental Psychology, 35, 478488.

Newstrom, J. W., \& Ruch, W. A. (1975). Marketing ethics of management and the management of ethics. MSU Business Topics, 23, 29-37.

Oliner, S. P., \& Oliner, P. M. (1988). The altruistic personality: Rescuers of Jews in Nazi Europe. New York: Free Press.

Paulhus, D. L. (1984). Two-component models of socially desirable responding. Journal of Personality and Social Psychology, 46, 598-609.

Podsakoff, P. M., MacKenzie, S. B., Lee, J. Y., \& Podsakoff, N. P. (2003). Common method biases in behavioral research: A critical review of the literature and recommended remedies. Journal of Applied Psychology, 88, 879-903.

Ray, L. (1998). Why we give: Testing economic and social psychological accounts of altruism. Polity, 30, 383-416.

Reed, A., II, \& Aquino, K. (2003). Moral identity and the expanding circle of moral regard toward out-groups. Journal of Personality and Social Psychology, 84, 1270-1286.

Rest, J. R. (1986). Moral development: Advances in research and theory. New York: Praeger.

Reynolds, S. J. (2003). Perceptions of organizational ethicality: Do inflated perceptions of self lead to inflated perceptions of the organization? Journal of Business Ethics, 42, 253-266.

Reynolds, S. J. (2006a). Moral awareness and ethical predispositions: Investigating the role of individual differences in the recognition of moral issues. Journal of Applied Psychology, 91, 233-243.

Reynolds, S. J. (2006b). A neurocognitive model of the ethical decisionmaking process: Implications for study and practice. Journal of Applied Psychology, 91, 737-748.

Schminke, M. S., Ambrose, M. L., \& Noel, T. W. (1997). The effect of ethical frameworks on perceptions of organizational justice. Academy of Management Journal, 40, 1190-1209.

Tajfel, H. (1959). Quantitative judgment in social perception. British Journal of Psychology, 50, 16-29.

Tajfel, H. (1974). Social identity and intergroup behavior. Social Science Information, 13, 65-93.

Tajfel, H., \& Turner, J. C. (1979). An integrative theory of intergroup conflict. In W. G. Austin \& S. Worchel (Eds.), The social psychology of intergroup relations (pp. 33-47). Monterey, CA: Brooks-Cole.

The StudyResponse Project. (n.d.). Retrieved August 23, 2007, from http:// studyresponse.syr.edu/studyresponse/index.htm

Toffler, B. L. (1986). Tough choices: Managers talk ethics. New York: Wiley.

Treviño, L. T., Weaver, G., \& Reynolds, S. J. (2006). Behavioral ethics in organizations: A review. Journal of Management, 32, 951-990.

Turner, J. C., \& Oakes, P. J. (1986). The significance of the social identity concept for social psychology with reference to individualism, interactionism, and social influence. British Journal of Social Psychology, 25, 237-252.

Vroom, V. H. (1964). Work and motivation. New York: Wiley.

Weaver, G. R., \& Treviño, L. K. (1994). Normative and empirical business ethics: Separation, marriage of convenience, or marriage of necessity? Business Ethics Quarterly, 4, 129-143.

Weber, J. (1990). Scenarios in business ethics research: Review, critical assessment, and recommendations. Business Ethics Quarterly, 2, 137160.

Widaman, K. F. (1985). Hierarchically nested covariance structure models for multitrait-multimethod data. Applied Psychological Measurement, 9, $1-26$.

Zuckerman, M., \& Reis, H. T. (1978). Comparison of three models for predicting altruistic behavior. Journal of Personality and Social Psychology, 36, 498-510.

Received September 26, 2006

Revision received March 26, 2007

Accepted May 22, 2007 